\title{
Total diz artoplastisi sonrası ekstansör mekanizma komplikasyonları: patella tendon yırtığı; kuadriseps tendon yırtığı; patella kırıkları
}

\author{
Complications of extensor mechanism after total knee arthroplasty: \\ patellar tendon rupture; quadriceps tendon rupture; patella fractures
}

\author{
Kerem Başarır ${ }^{1}$, Mustafa Onur Karaca²
}

\author{
${ }^{1}$ Ankara Üniversitesi Tıp Fakültesi, Ortopedi ve Travmatoloji Anabilim Dalı, Ankara \\ ${ }^{2}$ Çiğli Bölge Ĕgitim Hastanesi, Ortopedi ve Travmatoloji Kliniği, İzmir
}

\begin{abstract}
Diz ekstansör mekanizmasını içeren komplikasyonlar, total diz artroplastisi sonrası hastaların \%1-12'sinde görülür ve hasta klinik sonuçları ve memnuniyeti üzerinde önemli olumsuz etkileri vardır. Bu derleme en sık karşılaşılan diz ekstansör mekanizması komplikasyonlarından olan patella tendon yırtığı, kuadriseps tendon yırtığı ve periprostetik patella kırığına odaklanmaktadır. Bu raporda diz ekstansör mekanizmasının anatomisi gözden geçirilecek, ameliyat sonrası gelişebilecek komplikasyonlar açısından riskli hastaları belirleyebilmek için risk faktörleri ayrıntılandırılacak, tanı algoritmaları ve mevcut tedavi olanakları değerlendirilecektir. Bu komplikasyonların tedavisinde çeşitli cerrahi teknikler geliştirilmiş olmasına rağmen, total diz artroplastisi sonrasında gelişen komplikasyonlarda ekstansör mekanizmayı ve hasta beklentilerini etkili bir şekilde yönetmek güçtür.
\end{abstract}

Anahtar sözcükler: artroplastiler; diz replasman; diz yaralanmaları; patellar tendon; kuadriseps femoris; patella

\begin{abstract}
The complications involving knee extensor mechanism are seen in $1 \%$ to $12 \%$ of patients after total knee arthroplasty, and have significant negative effects on patient outcomes and satisfaction. This review focuses on three of the most common problems: patellar tendon disruption, quadriceps tendon rupture, periprosthetic patellar fracture. The purpose of this report is to review the relevant anatomy of the knee extensor mechanism, present the current risk factors that may lead to extensor mechanism complications, provide diagnosis algorithms and treatment options. Although various surgical techniques have been developed, it is difficult to effectively manage the extensor mechanisms and patient expectations in complications after total knee arthroplasty.
\end{abstract}

Key words: arthroplasties; knee replacement; knee injuries; patellar tendon; quadriceps femoris; patella

sıklığı \%1-12 arasında rapor edilmekte olup tedavileri oldukça zor ve sonuçları da tatmin edici olmaktan uzaktır. ${ }^{[1]}$ Cilde yakın bölgede meydana gelen yaralanmaların açık tedavisi sonrası enfeksiyon, yüksek mekanik kuwetler olmamasına karşın kötü biyolojik ortam nedeniyle yetersiz iyileşme ve tekrarlayan yırtıklar bu bölgenin önemli tedavi sorunlarını oluşturur. Bu nedenle, ekstansör mekanizma yaralanmalarından korunmak amacıyla, riskli hasta gruplarının ameliyat öncesinde tespiti büyük önem taşımaktadır.

Bu bölümde, ekstansör mekanizma komplikasyonla-

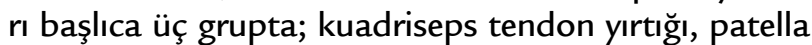
kırığı ve patella tendon yaralanması başııkları altında incelenecektir.

- Illetişim adresi: Doç. Dr. Kerem Başarır, Ankara Üniversitesi Tıp Fakültesi Ortopedi ve Travmatoloji, İbni Sina Hastanesi Ek Bina 1. Kat, Sıhhiye, Ankara Tel: 0312 - 3052321 e-posta: basarirkerem@yahoo.com

- Geliș tarihi: 19 Aralık 2018 Kabul tarihi: 19 Aralık 2018 


\section{PATELLA TENDON YIRTIĞI}

Genellikle tuberositas tibiada bulunan yapışma bölgesinden meydana gelen patella tendon yırtığı total diz artroplastisi yapılan hastaların \%1'inden azını ilgilendiren oldukça nadir bir komplikasyondur. Tuberositas tibia yapışma bölgesinden sonra, daha az sıklıkla tendon içi ve infrapatellar yırtıklar meydana gelmektedir. ${ }^{[1,2]}$

Riskli grup, özellikle patellar tendonun hareketliliğinin azaldığı durumların görüldüğü hastalardan oluşur. Bu durumlar arasında; patella baja, geçirilmiş patellar cerrahi ve dizde hareket kısıtlılığı sayılabilir. Ameliyat sırasında sıkı dizde zorlayıcı hareket veya tibial kesi sırasında kesici etkisi en sık mekanizmalardır (Şekil 1a). Ameliyat sonrası dönemde ise genellikle diz fleksiyon pozisyonunda düşme sonrasında görülür. Travma olmaksızın yırtıklar ise tibial polietilen insert'in patellar tendon üstündeki tekrarlayıcı teması veya sıkışması sonrası görülebilir. ${ }^{[2]}$

Patella tendon yırtığı olan hastalar, genellikle dizde ağrı, şişlik, ekstansör yetmezlik, düz bacak testinde beceriksizlik ve infrapatellar yumuşak doku defekti ile başvururlar. Ameliyat sırasında ekstansör mekanizmada gevşeme açık cerrahi sırasında görülebilirken, ameliyat sonrası yaralanmalarda yan grafilerde patella altaya ek olarak ultrasonografi ile de tanı konulabilir. Şüphede kalınan durumlarda ise manyetik artefakt düzeltici sekanslar da kullanılarak, tanıda yırtık ve yeri ortaya konulabilir.

Tedavi seçenekleri; tendon yırtığının konumu, doku kalitesi, hastanın yaşı, aktivite ve ihtiyaçlarına bağlıdır. Atelleme ile tedavi; parsiyel yırtığı olan, cerrahiye uygun olmayan veya fonksiyonel kapasitesi düşük olan hastalarda düşünülebilir. Enfeksiyon varlığında artrodez de yapılabilir.

Ameliyat sırasında gelişen veya akut yırtıkların tedavisi primer tamirdir. ${ }^{[3,4]}$ Bu amaçla, zımba (staple) veya sütür ankor kullanımını da içeren birçok yöntem tanımlanmıştır. Buna ek olarak, doku kalitesinin iyi olmadığı durumlarda veya kronik yırtıklarda mutlaka takviye (augmentation) yöntemleri eklenmelidir. Takviye amaciyla biyolojik materyaller (hamstring otogreft, Aşil tendon allogreft, ekstansör mekanizma allogreft gibi) kullanılabileceği gibi sentetik materyaller de (Marlex mesh; monofilament polypropylene gibi) kullanılabilir (Şekil 1b). ${ }^{[5,6]}$ Sentetik materyallerin uygulanması konusunda en bilinen teknik, Browne ve Hanssen'in tanımladığı; patellar tendonun katlanan sentetik materyalin tibia içerisindeki bir oluğa yerleştirilmesi temeline dayanır. ${ }^{[7]}$
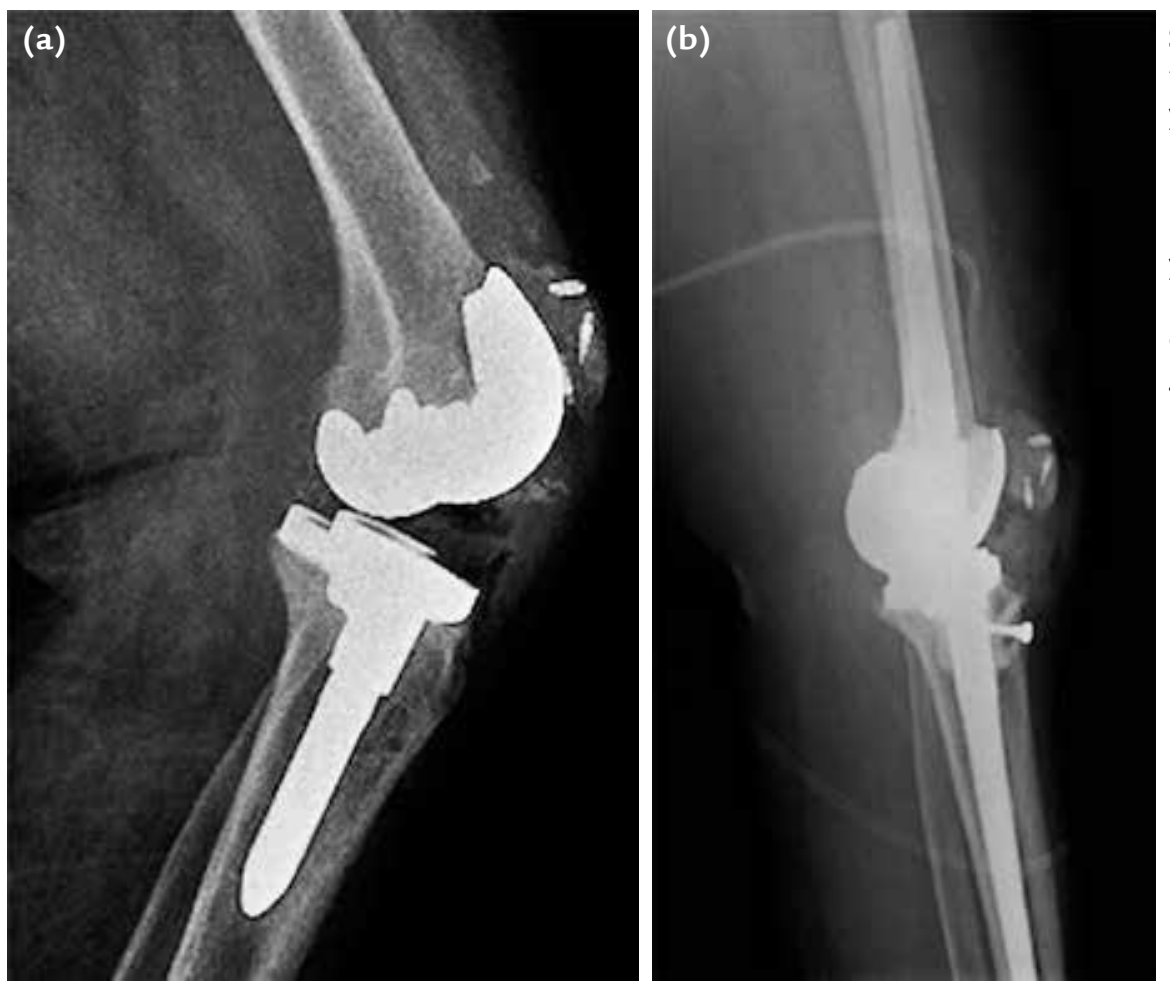

Şekil 1. a, b. Direkt lateral grafide patellanın sağlam kemik yapısı ile birlikte yüksek yerleşimi görülmektedir. Bu durum, ekstansör mekanizmanın distal kısmında,patellar tendonda yırtığı işaret etmektedir (a). Kronik dönemdeki yaralanmanın cerrahi tedavisinde primer tamire ek olarak mesh greft, kemik çimentosu ve vida yardımı ile takviye gözlenmektedir (b). 


\section{KUADRISEPS TENDON YIRTIĞI}

Total diz artroplastisi sonrası kuadriseps tendon yırtığı son derece nadir görülmektedir $(\% 0,1)$. Özellikle tendonun patella yapışma kısmını etkileyebilecek aşırı patella kemik kesisi, daha önce uygulanmış olan kuadriseps snip veya kuadriseps V-Y devirme (turndown) işlemi bu komplikasyon için önemli risk faktörlerini oluşturur. ${ }^{[8-10]}$ Ameliyat sonrası dönemde travmaya ikincil gerçekleşmesi, yırtıkların yaklaşık yarısını oluşturur.

Hastalar, patella tendon yırtığında olduğu gibi, ekstansör yetmezlik, düz bacak kaldırmada güçlük ve palpe edilebilen yumuşak doku boşluğu ile başvurabilir.

Ayrılmanın miktarı tedaviyi yönlendiren önemli bir faktördür. Kısmi yırtıklarda alçı veya atel ile uygulanabilen konservatif tedavi hemen daima iyi sonuçlanır. ${ }^{[9]}$ Ancak, 20\%'den fazla ekstansör eksiklik ile karakterize olan tam kat yırtıklarda cerrahi tedavi uygulanabilir. Bu endikasyonda uygulanan cerrahi tedavi sonrası \%100'e ulaşan yüksek komplikasyon oranları ile üçte bire ulaşan tekrar yırtık oranları bildirilmektedir. Bu nedenle, tamir tekniği içerisine yırtığın yerine ve kemik kalitesine göre sütür ankor, hamstring otogreft gibi materyaller ile takviye (augmentation) önerilmektedir.

\section{PATELLA KIRIKLARI}

Ekstansör mekanizmanın en sık görülen devamsızlık nedeni olan patella kırıkları, farklı serilerde $\% 0,5$ ile $\% 5$ arasında rapor edilmektedir. ${ }^{[1,11]}$ Yaklaşık on kata varan bu farkın temel nedeni, farklı serilerdeki patellar yüzey değişim oran ve teknikleridir (Şekil 2. a-c)
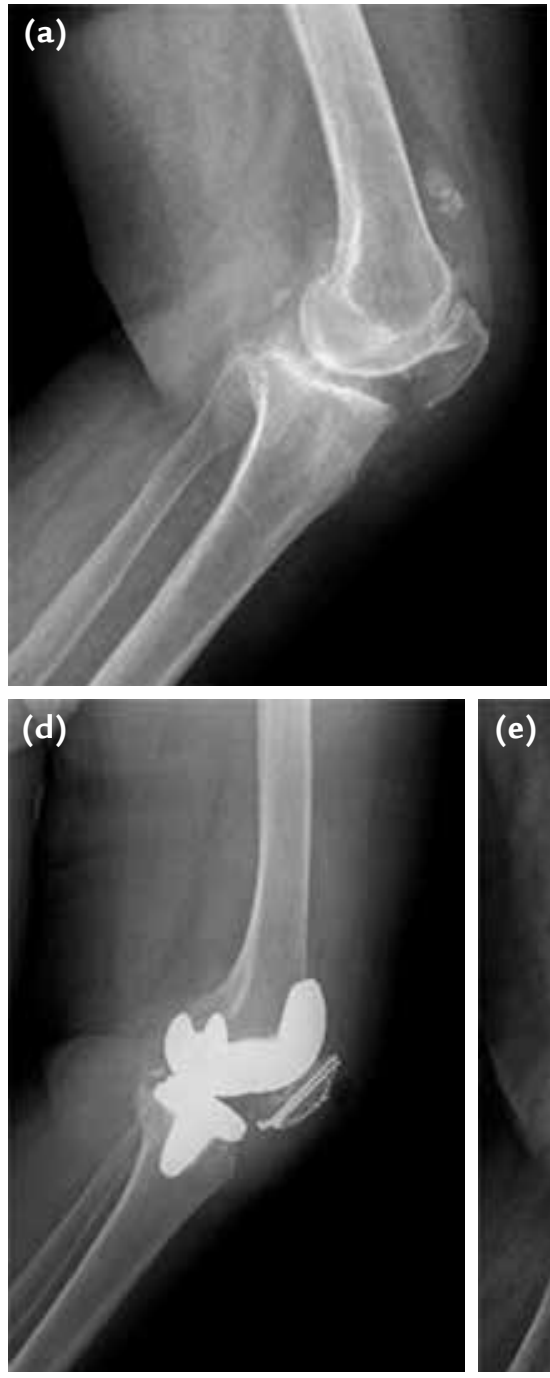
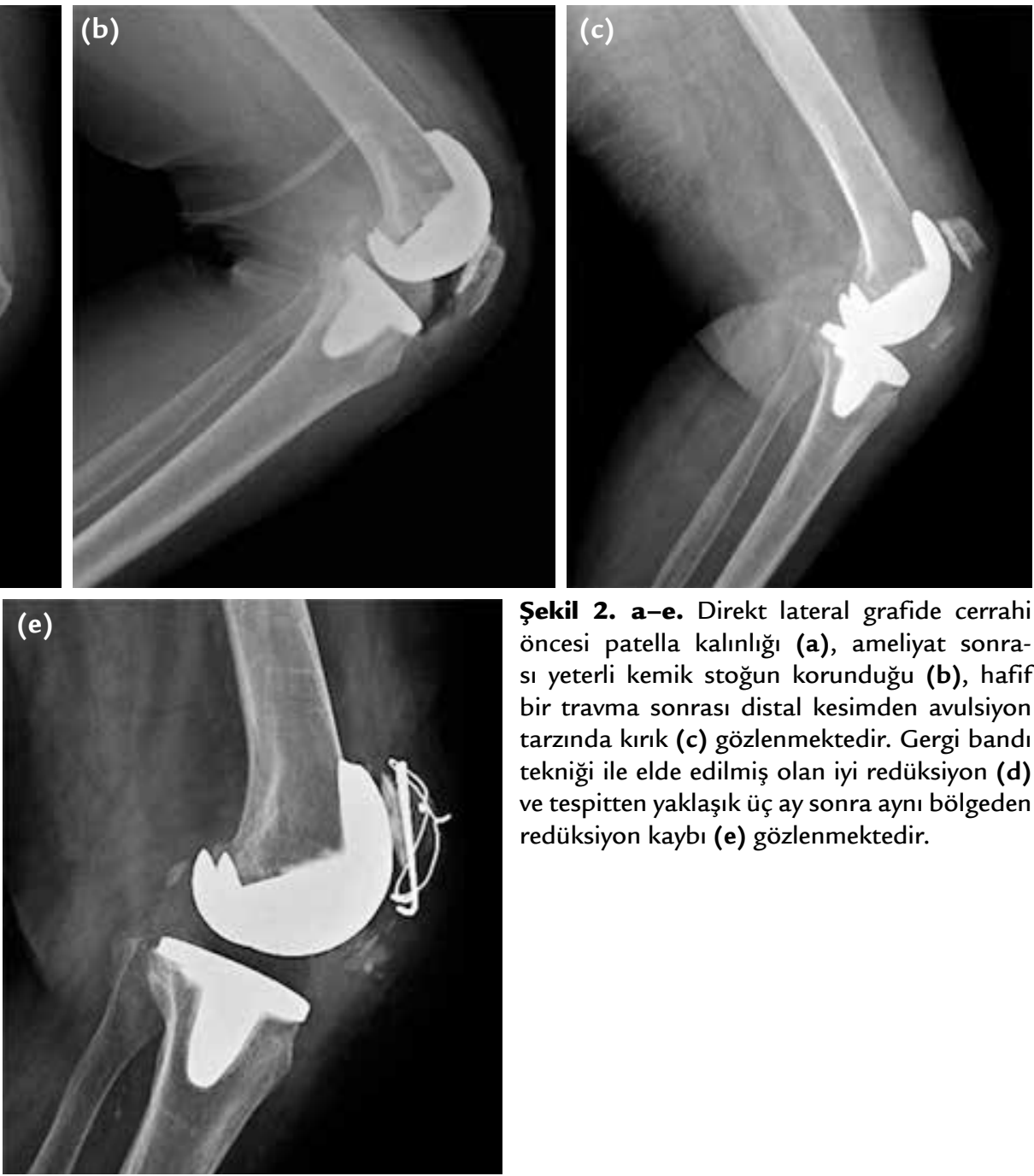

Şekil 2. a-e. Direkt lateral grafide cerrahi öncesi patella kalınlığı (a), ameliyat sonrası yeterli kemik stoğun korunduğu (b), hafif bir travma sonrası distal kesimden avulsiyon tarzında kırık (c) gözlenmektedir. Gergi bandı tekniği ile elde edilmiş olan iyi redüksiyon (d) ve tespitten yaklaşık üç ay sonra aynı bölgeden redüksiyon kaybı (e) gözlenmektedir. 
Kalan patella kemiğini zayıflatacak aşırı patella kesisi, büyük peg deliği ve osteoporoz bu açıdan önemli risk faktörlerini oluşturur. Diğer yandan, patella üzerine binen yükleri arttıran femur ve tibia malrotasyonu ile obezite ve osteoporoz, diğer risk faktörleri arasında sayılabilir.

Patella kırıkları, dizin ön yüzünde direkt travmayla meydana gelebileceği gibi kuadriseps kasının eksentrik kasılmasına sekonder avulsiyon kırı̆̆ı şeklinde de oluşabilir. Ameliyat sonrası dönemde ön diz ağrısı, şişlik ve ekstansör yetmezlik temel bulgulardır. Tanı için öncelikle lateral diz grafisi ve klinik şüphe halinde bilgisayarlı tomografi çekilmelidir.

Periprostetik patella kırıkları için birçok sınıflama sistemi önerilmekle birlikte, Ortiguera ve Berry'nin önerdikleri sınıflama, özellikle implant stabilitesi ve ekstansör mekanizma devamlılığının birlikte değerlendirilmesi nedeniyle sık kullanılmaktadır. ${ }^{[12]}$

Buna göre: Tip I stabil bir implant ve devamlı bir ekstansör mekanizma; Tip II stabil implant ancak devamsız bir ekstansör mekanizma; Tip III instabil bir implant ve devamsız bir ekstansör mekanizmayı temsil eder. Tip III ek olarak patellar kemiğin durumuna göre iyi kemik stoğunda Tip IIla, kötü kemik stoğunda Tip IIlb olarak sınıflanır.

Tedavi yöntemi, kırığın yeri ve tipi, implant stabilitesi, kalan kemik stoğu ve ekstansör mekanizmanın bütünlüğüne göre seçilir. Tip I kırıklarda konservatif tedavi genellikle çok iyi sonuç verir. Ancak, patellar kırığın tespiti gereken ve ekstansör mekanizmanın devamsız olduğu Tip II ve IIla olgularda cerrahi tedavi genel olarak tatmin edici sonuç vermez (Şekil 2 . d, e). Bu hasta grubunda \%40-50 komplikasyon ve yarıdan fazla ekstansör kayıp bildirilmektedir. ${ }^{[12,13]}$ Kemik stoğunun tespit için yetersiz olduğu olgularda ise patellektomi bir tedavi seçeneği olarak değerlendirilmelidir. ${ }^{[2]}$

\section{KAYNAKLAR}

1. Nam D, Abdel MP, Cross MB, LaMont LE, Reinhardt KR, McArthur BA, Mayman DJ, Hanssen AD, Sculco TP. The management of Extensor Mechanism Complications in total knee arthroplasty. J Bone Joint Surg Am 2014;96(6):e47. Crossref

2. Parker DA, Dunbar MJ, Rorabeck $\mathrm{CH}$. Extensor mechanism failure associated with total knee arthroplasty: prevention and management. J Am Acad Orthop Surg 2003;11(4):238-47. Crossref

3. Rand JA, Morrey BF, Bryan RS. Patellar tendon rupture after total knee arthroplasty. Clin Orthop Relat Res 1989;(244):233-8. Crossref

4. Schoderbek RJ Jr, Brown TE, Mulhall KJ, Mounasamy V, Iorio R, Krackow KA, Macaulay W, Saleh KJ. Extensor mechanism disruption after total knee arthroplasty. Clin Orthop Relat Res 2006;446:176-85. Crossref

5. Springer BD, Della Valle CJ. Extensor mechanism allograft reconstruction after total knee arthroplasty. J Arthroplasty 2008;23(7 Suppl):35-8. Crossref

6. Cadambi A, Engh GA. Use of a semitendinosus tendon autogenous graft for rupture of the patellar ligament after total knee arthroplasty. A report of seven cases. J Bone Joint Surg Am 1992;74(7):974-9. Crossref

7. Browne JA, Hanssen AD. Reconstruction of patellar tendon disruption after total knee arthroplasty: results of a new technique utilizing synthetic mesh. J Bone Joint Surg Am 2011;93(12):1137-43. Crossref

8. Lynch AF, Rorabeck $\mathrm{CH}$, Bourne RB. Extensor mechanism complications following total knee arthroplasty. J Arthroplasty 1987;2(2):135-40. Crossref

9. Dobbs RE, Hanssen AD, Lewallen DG, Pagnano MW. Quadriceps tendon rupture after total knee arthroplasty. Prevalence, complications, and outcomes. J Bone Joint Surg Am 2005;87(1):37-45. Crossref

10. Yun AG, Rubash HE, Scott RD, Laskin RS. Quadriceps rupture associated with a proximal quadriceps release in total knee arthroplasty. A report of three cases. J Bone Joint Surg Am 2003;85(9):1809-11. Crossref

11. Hozack WJ, Goll SR, Lotke PA, Rothman RH, Booth REJr. The treatment of patellar fractures after total knee arthroplasty. Clin Orthop Relat Res 1988;(236):123-7. Crossref

12. Ortiguera CJ, Berry DJ. Patellar fracture after total knee arthroplasty. J Bone Joint Surg Am 2002;84(4):532-40. Crossref

13. Chalidis BE, Tsiridis E, Tragas AA, Stavrou Z, Giannoudis PV. Management of periprosthetic patellar fractures. A systematic review of literature. Injury 2007;38(6):714-24. Crossref 